\title{
Cultural Capital and Educational Attainment
}

Alice Sullivan Nuffield College

Oxford

England

Alice.Sullivan@nuf.ox.ac.uk 
Abstract

According to Bourdieu's theory of cultural reproduction, children from middle class families are advantaged in gaining educational credentials due to their possession of cultural capital. In order to assess this theory, I have developed a broad operationalisation of the concept of cultural capital, and have surveyed pupils on both their own and their parents' cultural capital. I will conclude that cultural capital is transmitted within the home and does have a significant effect on performance in the GCSE (General Certificate of Secondary Education) examinations. However, a large, direct effect of social class on attainment remains when cultural capital has been controlled for. Therefore, 'cultural reproduction' can provide only a partial explanation of social class differences in educational attainment. 


\section{Introduction}

This paper will assess the merits of the cultural reproduction approach to the examination of class and gender differentials in educational attainment.

I will address the following questions:

- How cultural capital is distributed according to social class and educational level.

- The extent to which cultural capital is passed down from parents to children.

- What effect cultural capital has on GCSE attainment at age 16.

\section{Cultural Capital}

Bourdieu states that cultural capital consists of familiarity with the dominant culture in a society, and especially the ability to understand and use "educated" language. $\mathrm{He}$ argues that the possession of cultural capital varies with social class, yet the education system assumes the possession of cultural capital. This makes it very difficult for lower class pupils to succeed in the education system.

'By doing away with giving explicitly to everyone what it implicitly demands of everyone, the educational system demands of everyone alike that they have what it does not give. This consists mainly of linguistic and cultural competence and that relationship of familiarity with culture which can only be produced by family upbringing when it transmits the dominant culture.' (Bourdieu 1977: 494)

Since, according to Bourdieu, the educational system presupposes the possession of cultural capital, which only a minority of students in fact possess, there is a great deal 
of inefficiency in "pedagogic transmission". This is because students simply do not understand what their teachers are trying to get across. For Bourdieu, this is particularly apparent in the universities, where students, afraid of revealing the extent of their ignorance '...minimise the risks by throwing a smoke-screen of vagueness over the possibility of truth or error.' (Bourdieu and Passeron 1977, 1990: 114)

But despite the fact that lower class pupils are seriously disadvantaged in the competition for educational credentials, the results of this competition are seen as meritocratic and therefore as legitimate. In addition, Bourdieu claims that social inequalities are legitimated by the educational credentials held by those in dominant positions. This means that the educational system has a key role in maintaining the status quo.

‘...it [education] is in fact one of the most effective means of perpetuating the existing social pattern, as it both provides an apparent justification for social inequalities and gives recognition to the cultural heritage, that is, to a social gift treated as a natural one.' (Bourdieu, 1974: 32)

In sum, Bourdieu's view is that cultural capital is inculcated in the higher-class home, and enables the higher-class student to gain higher educational credentials than the lower class student. This enables higher-class individuals to maintain their class positions, and legitimates the dominant positions that they typically go on to hold. Of course, some lower-class individuals will succeed in the educational system, but, rather than challenging the system, this will strengthen it by contributing to the appearance of meritocracy.

Bourdieu can be criticised for not being precise enough about exactly which of the resources associated with the higher-class home constitute cultural capital, and how 
these resources are converted into educational credentials. Indeed, he might himself be accused of '...throwing a smoke-screen of vagueness over the possibility of truth or error.' However, I think that the concept of cultural capital is substantive enough to be operationalised, although Bourdieu does not make it at all obvious how this should be done. I will go on to discuss Bourdieu's own attempt to apply empirical evidence to his theory.

\subsection{Bourdieu's Own Evidence}

Bourdieu is adamant that he does not engage in theory for its own sake, and that empirical work is central to his enterprise.

'Let me say outright and very forcefully that I never 'theorise', if by that we mean engage in the kind of conceptual gobbledegook... that is good for textbooks and which, through an extraordinary misconstrual of the logic of science, passes for Theory in much of Anglo-American social science... There is no doubt a theory in my work, or, better, a set of thinking tools visible through the results they yield, but it is not built as such... It is a temporary construct which takes shape for and by empirical work.' (Waquant 1989: 50).

Unfortunately, the claim that Bourdieu's theoretical framework is subordinate to the needs of empirical research is not backed by the evidence provided by Bourdieu regarding cultural reproduction.

For Bourdieu's theory to be backed empirically, he would need to show that:

1) parental cultural capital is inherited by children.

2) children's cultural capital is converted into educational credentials. 
3) educational credentials are a major mechanism of social reproduction in advanced capitalist societies.

Of course, Bourdieu does not deny that privilege can be inherited through means other than the acquisition of educational credentials. Inheritance of property, and occupational advantage gained through social networks are obvious examples of this. So, Bourdieu's theory is not refuted by empirical evidence that there is no one-to-one correspondence between credentials and occupational outcomes (see for instance Dale and Pires 1984). However, it is crucial to Bourdieu's theory that cultural capital actually does facilitate educational success, and that educational success actually is associated with occupational advantage, even if this is only a means of legitimating class inequalities.

Bourdieu claims that (1) and (2) are shown:

'...by the fact that, among the pupils of the grandes écoles, a very pronounced correlation may be observed between academic success and the family's cultural capital measured by the academic level of the forbears over two generations on both sides of the family...' (Bourdieu 1977: 497).

Bourdieu is not entitled to assume that a high parental level of education reveals a high level of parental cultural capital. In fact, Bourdieu's use of parental educational credentials as a measure of cultural capital begs the question of whether educational credentials simply constitute '...embodied cultural capital that has received school sanctioning.' (Bourdieu and Boltanski 1981:145). In addition, the use of bivariate analyses is crude. Clearly, a simple association between two variables is not convincing evidence of a causal relationship. Bourdieu fails to show that parental cultural capital is inherited by the children, and that this is the mechanism through 
which higher-class pupils tend to attain higher educational credentials than lowerclass pupils. His evidence is quite consistent with educational privilege being passed down through mechanisms other than cultural capital, such as parental encouragement and material resources.

Bourdieu also presents evidence that both social class and educational attainment are strongly associated with participation in cultural activities such as book reading and buying, and cinema, theatre, concert and museum attendance. (Ibid.: 490-492). However these figures are insufficient to back up Bourdieu's theory. They do not constitute evidence that participation in cultural activities is the mechanism by which middle class parents ensure good qualifications for their children.

In sum, Bourdieu assumes much of what he sets out to prove. It is circular to treat educational level as a proxy for cultural capital if one is trying to assess whether cultural capital does in fact help to determine the educational levels reached by individuals.

\subsection{Operationalisation}

Bourdieu's concept of cultural capital is not clearly defined, and it is not particularly surprising that it has been operationalised in various different ways by subsequent researchers. I have argued that Bourdieu's own operationalisation of the concept is quite inadequate. Yet Bourdieu is not the only author to use parental education as a proxy for cultural capital. For instance, Halsey, Heath and Ridge (1980) use this proxy, as do Robinson and Garnier (1985) and Jonsson (1987).

Since Bourdieu's definition of cultural capital is not precise, it is not clear what an 'authentic' operationalisation would consist of. However, Bourdieu does explicitly 
state the importance of linguistic competence. Cultural 'competence' and 'familiarity' can reasonably be interpreted as knowledge of and participation in the dominant culture. Despite this, previous investigations of cultural capital have not included data on linguistic ability, and DiMaggio (1982) and DiMaggio and Mohr (1985) are unusual in using data on cultural knowledge. Data on cultural activities other than reading has often tended towards highly exclusive activities such as gallery attendance, which are foreign to a large proportion even of the middle and upper classes. For example, P.M. De Graaf (1986) uses a measure of the number of visits per month to museums, galleries, concerts, theatres and historical buildings. In general, surveys include data on either pupils' or parents' cultural capital, but not both. Most commonly, the proxy of parental education is used instead of data on parental cultural capital, although this proxy clearly begs the question of whether occupational status and educational attainment actually do reflect the possession of cultural capital. Given that researchers have operationalised the concept of cultural capital in different ways, it is not surprising that empirical studies of the effect of cultural capital on educational attainment have varied in their conclusions. As well as those already mentioned, note Crook (1997), Egerton (1997), Graetz (1988), Kalmijn and Kraaykamp (1996), Katsillis and Rubinson (1990) and Savage and Egerton (1997).

Which cultural attributes should be seen as constituting capital cannot be determined without empirical investigation, since the term cultural capital implies an analogy with economic capital, and therefore, a return. The return on cultural capital takes the form of educational credentials and, ultimately, occupational success. Therefore, I have used a broad operationalisation of cultural capital in order to examine which elements actually yield returns in the sense of contributing to educational success. 
If participation in cultural activities does lead to academic success, one may ask why this should be. It may be suggested that the culture of the school reflects the dominant culture. This could occur if teachers are prejudiced in favour of pupils who display 'cultured' traits, and therefore give them higher grades (Farkas et al. 1990). This view is perhaps most relevant in the US, where grades awarded by teachers are an important outcome of schooling. It is a less plausible explanation in nations such as Britain, where the key outcome of schooling is the results gained in national examinations. Alternatively, the dominant culture could be ingrained in the curriculum. However, it has been pointed out that, although this may be true of France, there is little emphasis on highbrow culture in schools in countries such as Britain, the Netherlands, and the US (De Graaf et al. 2000).

An alternative explanation is that participation in cultural activities leads to the development of knowledge or skills, which in turn enable pupils to succeed at school. For instance, one might expect reading novels to contribute to both linguistic competence and cultural knowledge. Crook (1997) and N.D. De Graaf et al. (2000) follow P.M. De Graaf $(1986,1988)$ in breaking cultural capital into two constituent parts, reading and beaux-arts participation. Beaux-arts participation refers to participation in formal cultural activities outside the home, such as gallery, theatre and concert attendance. Both Crook (1997) and N.D. De Graaf et al. (2000) find that reading is associated with academic success whereas beaux-arts participation is not, and infer from this that the effect of cultural capital on educational attainment is due to the 'educative resources' such as analytic and cognitive skills which are developed by reading, rather than to the communication of status via participation in formal culture. 
However, this inference may be questioned, since one could argue that participation in beaux-arts may contribute to the development of skills and knowledge, or that pupils' reading is as likely to prejudice teachers in their favour as is participation in other cultural activities. Therefore, as a further test of this hypothesis, it will be useful to test pupils on the sorts of abilities and knowledge that may be developed through cultural participation, in order to see whether these skills are in fact the means through which cultural participation promotes educational success.

In sum, many researchers examining cultural capital have used what data was available to them, even though this data has not been ideally suited to the purpose. In my view, it is far preferable to begin with an exploration of the theory of cultural reproduction, and of the mechanisms through which cultural capital may operate, in order to develop a sound operationalisation of the concept of cultural capital, and then to collect appropriate data.

\section{Methodology}

I surveyed pupils in their final year of compulsory schooling (i.e. 'year 11' students, about 16 years old) in England, in 1998. (I piloted the questionnaire in 1997). I chose to survey year 11 pupils because this allowed me to follow up on the GCSE results obtained subsequently by the pupils. The sample included four schools. Two of these were co-educational, two single-sex. All were comprehensive. Cultural reproduction theory is concerned with general processes, which are not contingent on any particular school context. Therefore, while a representative sample of the year 11 population might have been ideal, it should be borne in mind that I am not attempting to make population estimates, but rather to examine processes that the theory of cultural 
reproduction suggests should operate right across the educational system. As a student collecting data independently, my sample size was inevitably restricted. Therefore, I did not have the capacity to examine school type effects, and preferred to keep the variable 'school type' constant as far as possible by restricting my sample to the comprehensive sector.

I administered a questionnaire for self-completion by pupils. Pupils were not allowed to confer while completing the questionnaire. Pupils and schools were assured of the confidentiality of their responses.

In three out of the four schools, the entire year group was surveyed. In the remaining school, for time-tabling reasons, five out of seven forms were surveyed. Out of a potential sample of 557 pupils, 465 questionnaires were adequately completed, giving a response rate of 83.5 per cent. The majority of the non-response was due to absenteeism.

Taken as a whole, the sample provides a good spread in terms of social class. Schools 1 and 2 had a large proportion of service class families ( 44.8 per cent and 42 per cent respectively), compared to schools 3 and 4 where 14.7 and 30.8 per cent of families respectively were categorised as belonging to the service class ${ }^{1}$. The proportion of families categorised as belonging to the skilled or unskilled manual classes was higher in schools 3 and 4 (34.6 per cent and 28.6 per cent respectively) than in schools 1 and 2 (10.5 and 11 per cent respectively).

Parents' social class and educational credentials were determined from pupils' responses. The responses on parents' occupations were re-coded using a six-category version of the Goldthorpe class schema ${ }^{2}$, taking mother's or father's class, whichever 
was the higher, as determined by a simplified version of Erikson's (1984) dominance schema $^{3}$.

Mother's or father's qualifications were also selected according to which was higher.

The level of missing data on social class is 12 per cent $(57 \text { cases })^{4}$. This is mainly because many students did not respond to the question on their parents' occupations in sufficient detail for the responses to be categorised. In the case of parents' qualifications, this problem is still more severe (122 missing cases). Therefore, I have included these missing cases within my analyses as separate categories.

I have surveyed pupils on a broad range of possible components of cultural capital.

1. Activities

- Reading: type and amount of books read, library use, newspapers read.

- Television: type of TV programmes watched.

- Music: type of music listened to, playing an instrument.

- Participation in 'public' or 'formal' culture: art gallery, theatre and concert attendance.

2. Cultural Knowledge

- Tested knowledge of famous cultural figures.

3. Language

- Active and passive vocabulary test scores.

For a detailed description of these variables, see Sullivan (2000).

The data on reading includes the types of books read as well as the amount read. Both classic books and contemporary books of the sort that receive reviews in the quality 
press were categorised as having cultural capital content. When unsure of the category a book fell into, I used the 'Book Review Digest' database. This is a database of reviews from 100 English language journals such as the Times Literary Supplement and the New York Review of Books, from 1983 to the present. Given the role of prestigious journals such as the Times Literary Supplement in conferring legitimacy on high culture, this seems like a reasonable way of determining the cultural status of contemporary books.

Having asked pupils to list the television programmes they watched regularly, I categorised these programmes according to their cultural capital content. Factual TV programmes on science, arts or humanities and politics were categorised as having cultural capital content. Non-factual programmes that are sophisticated in terms of vocabulary and cultural references were also categorised as having cultural capital content. Pupils were given a point for each of the following categories that were included in the programmes they said they watched regularly: science (e.g. Horizon); arts (e.g. The Late Review); politics, current affairs and humanities (e.g. Newsnight); literary adaptations (e.g. Pride and Prejudice); and sophisticated comedies (e.g. Frasier).

The test of cultural knowledge consisted of asking pupils to categorise 25 famous cultural figures according to whether these figures are associated with politics, music, novels, art or science. This test is of course not intended to reflect all aspects of a pupil's cultural knowledge. However, it at least provides us with some indication of cultural knowledge, something that has been lacking in most previous research on cultural capital. Scores on this test were approximately normally distributed. Table 1 shows the percentage correct response for each of these items. Even the scores on the easiest items may seem shockingly low (1 in 10 do not know Einstein was a 
scientist!). Many figures who may be seen as part of the cultural mainstream are familiar only to a minority.

The test of passive vocabulary was a conventional 'sentence completion' test (see for instance Levy and Goldstein 1984). The test of active vocabulary demanded that pupils provide several synonyms for each of five words given.

I have also surveyed pupils on their parents' cultural activities. These activities include reading (and number of books in the home), newspapers taken, type of music and radio stations listened to, participation in 'formal culture', and the subjects discussed by parents in the home. It would have been difficult to get information directly from the parents, as many parents would no doubt have been reluctant to participate. It could be argued that pupils' responses regarding their parents are unreliable, as shared activities may be over-reported by pupils. However, note that De Graaf et al. (2000) find that respondents' own cultural practices have no effect on their reporting of their parents' cultural practices.

\section{Analysis}

\subsection{Parental Cultural Capital}

The first step in assessing the theory of cultural reproduction is to examine the distribution of cultural capital by social class and parental education. The parental cultural capital variable has mean 4.78 and standard deviation 3.89. Its maximum is 16. Service-class parents have a mean cultural capital score of 7.2, while non-serviceclass parents have a mean score of 3.6. Graduate parents have a mean score of 8.5 , while non-graduate parents have a mean score of 3.8. Both these differences are 
significant at the 0.001 level. Figures 1 and 2 show the association between class, education and cultural capital in the form of error bar charts.

\subsection{Pupils' Cultural Capital}

Having established an association between parental social class and cultural capital, we can move on to the question of whether cultural capital is transmitted within the home. To what extent is parental cultural capital associated with pupils' cultural capital, controlling for background variables?

\subsubsection{Activities}

[Table 2 here]

I used linear regression to analyse the determinants of the activities component of pupils' cultural capital. Table 1 shows two models. Model 1 includes parents' qualifications, parents' class, pupils' gender and school attended on pupils' cultural activities. Only significant parameters are shown, to save space. All of these variables except gender have significant effects at the 0.05 level. Having a graduate parent and having a higher service-class parent are significantly positively associated with pupils' cultural activities. Parents' cultural capital is introduced in Model 2. This shows that parents' cultural capital is by far the most important factor in accounting for the variation in pupils' cultural activities. Neither social class nor educational credentials are significant once parental cultural capital has been included. This shows that the effect of these background variables on pupils' cultural activities is mediated by parents' cultural capital. The effect of school attended is insignificant once parental cultural capital is taken into account. The absence of a school effect is important, as a crucial claim about cultural capital is that it is not transmitted by the school. (However, bear 
in mind the small number of schools in my sample, and that these are all comprehensive schools).

The Pearson correlation between parents' cultural capital and pupils' cultural activities is 0.617 ( $\mathrm{p} \leq 0.000)$. The strength of this relationship provides support for Bourdieu's view that cultural resources are strongly transmitted from parents to children.

\subsubsection{Language and Knowledge}

Pupils' tested vocabulary and cultural knowledge scores are modelled in tables 3 and 4. Parental cultural capital mediates the background variables to some extent, but not to the same extent as in the case of the activities component of cultural capital. This is unsurprising, as the parental cultural capital score is composed of similar items to the activities component of pupils' cultural capital, whereas I have no direct measure of parental vocabulary or cultural knowledge.

\section{[Table 3]}

Model 1 shows the effect of family characteristics, including parental cultural capital, on pupils' language scores. (Controls for sex and school attended are included in the model but not shown). Only significant parameters are shown. Parents' social class and qualifications are significant, but parents' cultural activities have the strongest effect.

Pupils' cultural activities are broken down into separate categories in order to determine which cultural activities are associated with pupils' vocabulary score. On Crook's (1997) view that public cultural participation serves to communicate status, whereas reading helps to develop abilities, reading should be positively associated 
with vocabulary and formal culture should not. And indeed, this is the case. But reading is not the only form of cultural participation that is positively and significantly associated with pupils' vocabulary. In fact TV viewing habits account for a greater proportion of the variation in pupils' vocabulary than does reading. The 'music' variable however, (whether a pupil listens to classical music and /or plays an instrument) is not significant.

\section{[Table 4]}

Using the same procedure for pupils' cultural knowledge, Model 1 shows that graduate parents are particularly strongly associated with cultural knowledge, but intermediate qualifications are also significant. Social class is not significant in this model, while parental cultural capital is.

Again, the effects of four categories of pupils' cultural activities are shown. I found the same pattern as for pupils' vocabulary. Reading has a significant association with pupils' cultural knowledge. Participation in formal culture does not. The 'music' variable is insignificant, whereas television viewing habits are significant.

These findings support the view that participation in formal or public culture does not foster the intellectual resources that may give an advantage at school, and that reading does foster these resources. However, reading is not the only cultural activity that is associated with linguistic ability and cultural knowledge. Watching relatively sophisticated programmes on TV is also associated with these skills. Of course, these associations cannot tell us whether reading and watching sophisticated TV programmes foster intelligence or whether pupils' reading and TV viewing habits simply reflect their level of measured intelligence. It seems highly likely that both of these processes occur. Ideally, one would control for measured ability at a given age 
(say 11 or younger) and then examine whether cultural participation has an effect on later performance in tests of ability and examinations controlling for the earlier ability score.

\subsection{GCSE attainment}

Finally, what impact does cultural capital have on grades achieved in the GCSE examinations? I have modelled GCSE results using a point score for the total of GCSEs gained - giving 1 point for a $\mathrm{G}$ grade, 2 for an $\mathrm{F}$ etc. This point score is approximately normally distributed.

\section{[Table 5]}

The effects of the background variables on pupils' GCSE scores are shown by Model 1. Compared to unskilled manual backgrounds, all non-manual backgrounds are associated with increased GCSE performance, with higher-service-class backgrounds providing the strongest advantage. Parents' qualifications in the degree and intermediate categories (A level or vocational) were significantly associated with GCSE scores. Model 2 shows that these effects are mediated to an extent by parental cultural capital. although intermediate qualifications are still significantly positive. Model 3 shows that the effect of parental cultural capital on pupils' GCSE scores is partially mediated by pupils' cultural activities. We can see that the effect of reading is significant, and the effect of participation in formal culture is insignificant. TV viewing habits are also significant (though just barely at the 0.05 level), and music is not significant. This follows the pattern that was seen in modelling pupils' linguistic ability and cultural knowledge.

Previously, I stated that, if participation in cultural activities is linked to examination success, this may be due to the development of knowledge or a set of competencies. 
Including scores for vocabulary and cultural knowledge in the model, we can see that the effects of parents' and pupils' cultural capital on GCSE attainment are indeed mediated in this way. In Model 3, parents' cultural capital and pupils' cultural activities both have highly significant effects. Once pupils' vocabulary and cultural knowledge scores are included, in Model 4, parents' cultural capital and pupils' cultural activities become insignificant. So, Model 4 shows very strong effects for both vocabulary and cultural knowledge, leaving no significant direct effects for parents' cultural capital or pupils' cultural activities. That the effects of these variables are entirely mediated by cultural knowledge and language ability is striking given that this is not the case for parental social class, which remains highly significant after the knowledge and language variables are added to the model. This suggests that the mechanism through which cultural participation improves educational attainment is in fact the possession of knowledge or a set of competencies, whereas the effect of social class cannot be explained in this way. The effect of parents' qualifications (barring the missing category) is rendered insignificant by the inclusion of knowledge and language scores in the model.

\section{Conclusions}

The concept of cultural capital has often been assimilated to the data available to researchers. By using data specifically designed to measure pupils' and parents' cultural capital, I have been able to provide a better test of Bourdieu's theory.

The first element of Bourdieu's theory that I set out to test is the claim that cultural capital is transmitted by higher-class parents to their children. I broke this down into two questions, firstly, what is the social distribution of cultural capital, and secondly, 
to what extent is cultural capital transmitted from parents to their children. I found that parental cultural capital is strongly associated with parental social class and with parental qualifications. These associations back Bourdieu's view that cultural capital is unequally distributed according to social class and education.

The view that cultural capital is transmitted from parents to their children is strongly supported in the case of pupils' cultural activities. This component of pupils' cultural capital varies by social class, but this variation is entirely mediated by parental cultural capital. Further evidence to back the view that cultural capital is transmitted in the home is the lack of a school effect in determining this component of pupils' cultural capital. The link between parental cultural capital and pupils' knowledge and language scores is weaker, but this is unsurprising given that my measure of parental cultural capital is a measure of activities. There is no school effect on the test of linguistic ability, and there is only a small school effect on cultural knowledge. This contrasts with a strong school effect on GCSE attainment, and suggests that linguistic ability and cultural knowledge are more strongly transmitted within the home than in the school. However, it must be borne in mind that my sample only contains four schools. Ideally one would collect a larger sample including different types of schools, as it is possible that school type might affect pupils' cultural capital. For instance, it is possible that private schools may instil cultural capital in pupils.

Pupils' reading and TV viewing habits each account for a significant proportion of the variance in linguistic ability and cultural knowledge, whereas participation in formal culture does not. This backs the view that reading develops the intellectual abilities of pupils, whereas participation in formal culture does not. This could be interpreted as supporting the views of Crook (1997) and N.D. De Graaf et al. (2000) that public cultural participation serves to communicate status, whereas private cultural 
consumption is a means of intellectual self-development. Television watching is not an indicator of cultural capital that has been used by previous authors, but $\mathrm{TV}$, in common with books, transmits information and may introduce an individual to new vocabulary and styles of expression. Note, however, that listening to classical music and playing an instrument are not associated with linguistic ability or cultural knowledge. Perhaps, then, the important distinction is not that of 'public' or 'formal' vs. 'private' or 'informal' cultural participation, but rather that of verbal or literary forms which use words to transmit information or content, vs. visual or musical forms which are not based on words and are therefore less likely to develop the skills that are rewarded within the school.

I went on to examine whether cultural capital affects pupils' educational attainment at GCSE level. The activities component of pupils' cultural capital is a significant determinant of pupils' GCSE score, as is parents' cultural capital. Again, reading and watching TV are the only significant elements of pupils' cultural participation. Of these, reading has by far the greater effect. These effects are entirely mediated by pupils' vocabulary and cultural knowledge. This firmly backs the view that the reason for the effect of cultural participation on academic attainment is that cultural participation is associated with intellectual resources which help pupils at school. This research gives no support to the view that teachers are prejudiced against workingclass pupils because of their lack of cultural capital. (Note that Hurrell (1995) has provided strong empirical evidence against the view that teachers are prejudiced against working-class pupils). Furthermore, in the British context of an enormous decline in the status of the teaching profession, it increasingly seems odd to portray teachers as an élite (cultural or otherwise) who are prejudiced against non-élite pupils. 
It may be argued that the association between cultural knowledge and GCSE attainment must be due to a bias towards high culture in the curriculum. However, it may be that pupils are rewarded highly in examinations and assessed coursework for demonstrating precisely that knowledge which they are unlikely to have gained within the school. This would be consistent with Bourdieu's claim that the school fails to give explicitly to everyone that which it implicitly demands of everyone. In this case, pupils from backgrounds poor in cultural capital may suffer most from a curriculum that is designed to avoid content and styles that are associated with the dominant culture. Furthermore, it seems unlikely that it would be possible, and certain that it would be undesirable, to introduce a form of assessment that would not reward linguistic ability or cultural knowledge, broadly defined.

Parents' social class retains a large and significant direct effect on GCSE attainment, controlling for the cultural capital variables. Therefore, it seems that cultural capital is one mechanism through which higher-class families ensure educational advantage for their children, but it leaves most of the social class differential in attainment unexplained. Other mechanisms, such as class differentials in material resources and educational aspirations must account for the remaining differential in educational attainment.

So, I have tried to give a fair test of Bourdieu's theory of cultural reproduction, and have found that, although it provides some useful insights, and helps to explain class differentials in educational attainment, it does not provide a complete account of these differentials. In line with Bourdieu's theory, cultural capital is associated with social class, and is transmitted from parents to children. Again, in line with Bourdieu's theory the possession of cultural capital does have a significant effect on GCSE 
attainment. However, this gives us only a partial explanation of class differentials in GCSE attainment.

I stated previously that one cannot say which cultural activities should be seen as 'capital' without an analysis into which cultural activities are associated with educational success. Reading and TV viewing habits are associated with GCSE attainment and with cultural knowledge and linguistic ability (which in turn are associated with GCSE success). This is evidence that it is reasonable to see these activities as cultural capital. There is no evidence here, on the other hand, that musical habits (listening and playing) or participation in formal culture constitute capital.

In sum, this work vindicates the usefulness of 'cultural capital' as an explanatory concept, but does not support the grand theory of 'cultural reproduction'.

ACKNOWLEDGEMENTS Many thanks to Anthony Heath and Geoffrey Walford. This work was funded by an ESRC studentship.

\footnotetext{
${ }^{1}$ The term 'service class' may be misleading, as it may suggest the service sector of the economy. In fact, in the context of the Goldthorpe class schema, the term 'service class' denotes positions of ownership and control.

${ }^{2} \mathrm{I}=1$ (service class, higher)

$\mathrm{II}=2$ (service class, lower)

$\mathrm{IIIa}+\mathrm{IIIb}=3$ (non-manual)

$\mathrm{IVa}+\mathrm{IVb}+\mathrm{IVc}=4$ (small proprietors)

$\mathrm{V}+\mathrm{VI}=5$ (skilled manual)

$\mathrm{VIIa}+\mathrm{VIIb}=6$ (unskilled manual)
} 
${ }^{3} 1$ dominates 2, 2 dominates 4, 4 dominates 3, 3 dominates 5, 5 dominates 6 .

${ }^{4}$ This is a normal level of non-response in national surveys where people are asked about their parents' occupations, such as the British Election Survey.

\section{Bibliography}

BOURDIEU, P. 1974. The School as a Conservative Force. In Eggleston, J. (ed.)

Contemporary Research in the Sociology of Education. London: Methuen.

BOURDIEU, P. 1977. Cultural Reproduction and Social Reproduction. In KARABEL, J. and HALSEY, A.H. (eds.) Power and Ideology in Education. Oxford: Oxford University Press.

BOURDIEU, P. and PASSERON, J-C. 1977, 1990. Reproduction in Education, Society and Culture. London: Sage.

BOURDIEU, P. and BOLTANSKI, L. 1981. The Education System and the Economy. In LEMERT, C.C. (ed.) Rupture and Renewal Since 1968. New York: Columbia University Press.

CROOK, C.J. 1997. Cultural Practices and Socioeconomic Attainment: The Australian Experience. Westport, Conneticut: Greenwood Press.

DALE, R. and PIRES, E. 1984. Linking People to Jobs. in BROADFOOT, P. (ed.) Selection, Certification and Control. London: Falmer.

DE GRAAF, P.M. 1986. 'The Impact of Financial and Cultural Resources on Educational Attainment in the Netherlands'. Sociology of Education 59, 4: 237-46.

DE GRAAF, P.M. 1988. 'Parents' financial and cultural resources, grades, and transition to secondary school in the Federal Republic of Germany.' European Sociological Review. 4, 3: 209-221.

DE GRAAF, N.D., DE GRAAF, P.M. and KRAAYKAMP, G. 2000. 'Parental Cultural Capital and Educational Attainment in the Netherlands: A refinement of the cultural capital perspective'. Sociology of Education. 73: 92-111.

DIMAGGIO, P. 1982. 'Cultural Capital and School Success'. American Sociological Review 47: 189-201.

DIMAGGIO, P. and MOHR, J. 1985. 'Cultural Capital, Educational Attainment, and Marital Selection'. American Journal of Sociology 90, 6: 1231-61.

EGERTON, M. 1997. 'Occupational Inheritance: The Role of Cultural Capital and Gender'. Work, Employment and Society 11, 2: 263-282.

ERIKSON, R. 1984. 'Social Class of Men, Women, and Families.' Sociology 18, 4: 500-514.

FARKAS, G. GROBE, R.P. SHEEHAN, D. and SHUAN, Y. 1990. 'Cultural resources and school success: Gender, ethnicity and poverty groups within an urban school district.' American Sociological Review 55: 127-142. 
GRAETZ, B. 1988. 'The Reproduction of Privilege in Australian Education'. British Journal of Sociology 39,3:358-76.

HALSEY, A.H., HEATH, A. and RIDGE, J. 1980. Origins and Destinations. Oxford: Clarendon Press.

HURRELL, P. 1995. 'Do Teachers Discriminate?'. Sociology 29, 1: 59-72.

JONSSON, J.O. 1987. 'Class Origin, Cultural Origin and Educational Attainment'. European Sociological Review 3, 3: 229-42.

KALMIJN, M. and KRAAYKAMP, G. 1996. 'Race, Cultural Capital and Schooling: An Analysis of Trends in the United States'. Sociology of Education 69: 22-34.

KATSILLIS, J. and RUBINSON, R. 1990. 'Cultural Capital, Student Achievement and Educational Reproduction'. American Sociological Review 55, 2: 270-279.

LEVY, P. and GOLDSTEIN, H. 1984. Tests in Education. London: Academic Press.

MACKINNON, D., STATHAM, J. and HALES, M. 1995. Education in the UK: facts and figures. Buckingham: Open University Press.

ROBINSON, R. and GARNIER, M. 1985. 'Class Reproduction among Men and Women in France'. American Journal of Sociology 91, 2: 250-58.

SAVAGE, M. and EGERTON, M. 1997. 'Social Mobility, Individual Ability and the Inheritance of Class Inequality’. Sociology 31, 4: 645-72.

SUlLIVAN, A. 2000. Cultural Capital, Rational Choice, and Educational Inequalities. D.Phil. Thesis, Oxford University.

WAQUANT, L.J.D. 1989. 'Towards a Reflexive Sociology: A Workshop with Pierre Bourdieu'. Sociological Theory 7, 3: 26-63. 


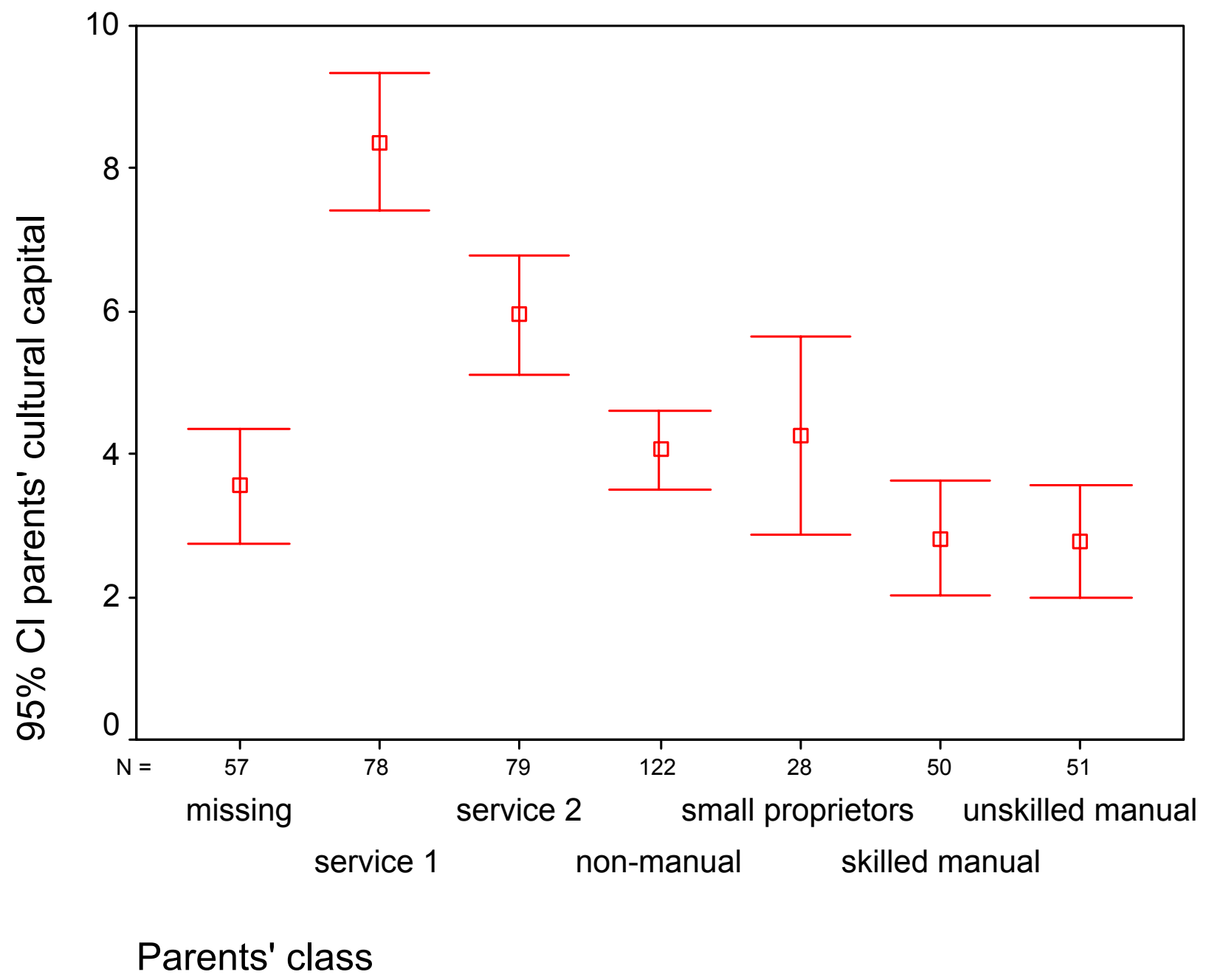

Fig. 1 Parents' class and Cultural Capital 


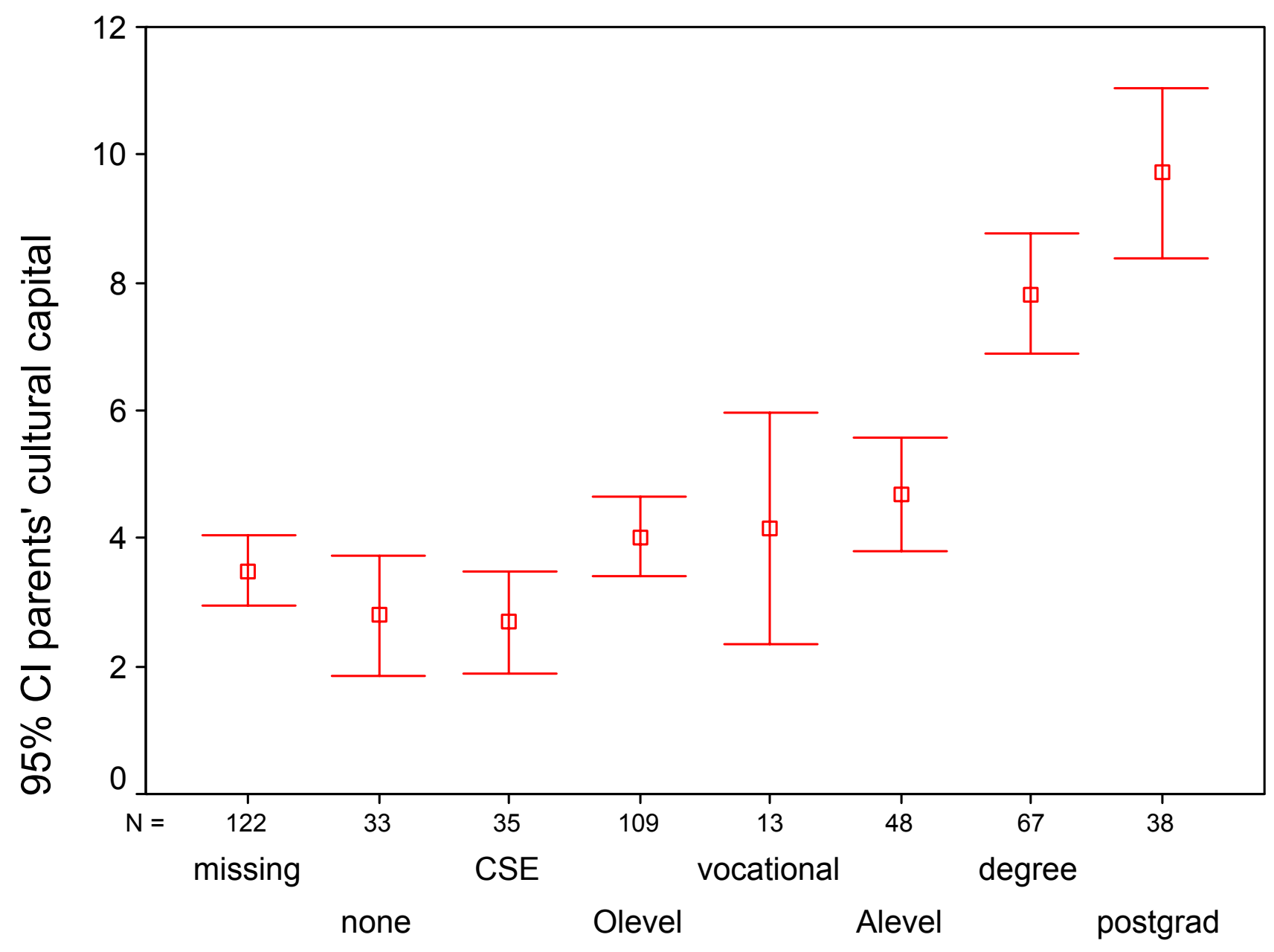

Parents' qualifications

Fig 2 Parents' Qualifications and Cultural Capital 
Table 1 Cultural Knowledge

\begin{tabular}{|l|l|}
\hline & $\%$ Correct Response \\
\hline Albert Einstein & 90 \\
\hline Galileo & 31 \\
\hline Marie Curie & 27 \\
\hline Louis Pasteur & 21 \\
\hline Stephen Hawking & 21 \\
\hline Charles Dickens & 89 \\
\hline Jane Austen & 76 \\
\hline Virginia Woolf & 23 \\
\hline Graham Greene & 7 \\
\hline Martin Amis & 5 \\
\hline Bill Clinton & 94 \\
\hline John F. Kennedy & 89 \\
\hline Mahatma Gandhi & 47 \\
\hline Gordon Brown & 33 \\
\hline Karl Marx & 25 \\
\hline Wolfgang Mozart & 81 \\
\hline Rachmaninov & 18 \\
\hline Johannes Brahms & 15 \\
\hline Miles Davis & 12 \\
\hline George Gershwin & 10 \\
\hline Vincent van Gogh & 85 \\
\hline Pablo Picasso & 72 \\
\hline Claude Monet & 49 \\
\hline Rembrandt & 29 \\
\hline Andy Warhol & 23 \\
\hline
\end{tabular}


Table 2. Pupils' Cultural Activities

\begin{tabular}{|l|l|l|}
\hline & Model 1 & Model 2 \\
\hline & $\mathrm{B}$ & $\mathrm{B}$ \\
\hline Intercept & $\begin{array}{l}4.161 \\
(0.422)^{* * *}\end{array}$ & $\begin{array}{l}3.328 \\
(0.377)^{\star * *}\end{array}$ \\
\hline Degree & $\begin{array}{l}1.705 \\
(0.416)^{* * *}\end{array}$ & $\begin{array}{l}0.408 \\
(0.381)\end{array}$ \\
\hline $\begin{array}{l}\text { CSE or no } \\
\text { qualificatio } \\
\text { ns }\end{array}$ & 0 & 0 \\
\hline $\begin{array}{l}\text { Service } \\
\text { class - } \\
\text { higher }\end{array}$ & $\begin{array}{l}1.345 \\
(0.461)^{* *}\end{array}$ & $\begin{array}{l}0.295 \\
(0.414)\end{array}$ \\
\hline $\begin{array}{l}\text { Unskilled } \\
\text { manual }\end{array}$ & 0 & 0 \\
\hline $\begin{array}{l}\text { Parents' } \\
\text { cultural } \\
\text { activities }\end{array}$ & $\begin{array}{l}0.355 \\
(0.030)^{* * *}\end{array}$ \\
\hline $\mathrm{N}$ & 465 & 465 \\
\hline
\end{tabular}

Significance levels denoted by ${ }^{*} p \leq .05,{ }^{* *} p \leq .01,{ }^{* * *} p \leq .001$. (Controls for sex and school, only significant parameters shown). 
Table 3. Pupils' Language Score

\begin{tabular}{|l|l|l|}
\hline & Model 1 & Model 2 \\
\hline & $\mathrm{B}$ & $\mathrm{B}$ \\
\hline Corrected Model & $0.213^{* * *}$ & $0.247^{\star * *}$ \\
\hline Intercept & 13.876 & 11.336 \\
& $(1.546)^{\star * *}$ & $(1.625)^{\star * *}$ \\
\hline Degree & 3.332 & 3.076 \\
& $(1.551)^{\star}$ & $(1.520)^{\star}$ \\
\hline Intermediate & 3.798 & 3.719 \\
& $(1.471)^{\star}$ & $(1.441)^{\star}$ \\
\hline CSE or no & 0 & 0 \\
qualifications & & \\
\hline Service class - & 4.575 & 4.165 \\
higher & $(1.718)^{\star *}$ & $(1.685)^{\star}$ \\
\hline Unskilled manual & 0 & 0 \\
& & \\
\hline Parents' cultural & 0.528 & 0.220 \\
activities & $(0.128)^{\star * *}$ & $(0.144)$ \\
\hline Reading & & 0.746 \\
& & $(0.255)^{\star *}$ \\
\hline Formal & & -0.072 \\
& & $(0.524)$ \\
\hline Music & & -0.033 \\
& & $(0.576)$ \\
\hline TV & & 2.448 \\
& 431 & $(0.586)^{\star * *}$ \\
\hline $\mathrm{N}$ & & 431 \\
\hline
\end{tabular}


Table 4. Pupils' Knowledge Score

\begin{tabular}{|l|l|l|}
\hline & Model 1 & Model 2 \\
\hline & $\mathrm{B}$ & $\mathrm{B}$ \\
\hline Corrected Model & $0.365^{* * *}$ & $0.389^{* * *}$ \\
\hline Intercept & 5.906 & 4.656 \\
& $(0.773)^{\star * *}$ & $(0.820)^{\star * *}$ \\
\hline Degree & 2.706 & 2.567 \\
& $(0.765)^{\star * *}$ & $(0.752)^{\star * *}$ \\
\hline O level & 1.434 & 1.379 \\
& $(0.637)^{\star}$ & $(0.626)^{\star}$ \\
\hline CSE or no & 0 & 0 \\
qualifications & & \\
\hline Parents' class $=$ & -2.029 & -2.068 \\
missing & $(0.805)^{\star}$ & $(0.791)^{\star *}$ \\
\hline Unskilled manual & 0 & 0 \\
& & \\
\hline School 2 & $1.277(0.606)^{*}$ & $1.348(0.596)^{*}$ \\
\hline School 3 & $-1.255(0.559)^{*}$ & $-1.186(0.550)^{*}$ \\
\hline School 4 & 0 & 0 \\
\hline Parents' cultural & 0.423 & 0.284 \\
activities & $(0.063)^{\star * *}$ & $(0.071)^{\star * *}$ \\
\hline Reading & & 0.493 \\
& & $(0.128)^{\star * *}$ \\
\hline Formal & & -0.123 \\
& & $(0.260)$ \\
\hline Music & & -0.145 \\
& & $(0.291)$ \\
\hline TV & & 0.817 \\
& 445 & $(0.282)^{\star *}$ \\
\hline N & 445 \\
\hline
\end{tabular}


Table 5. GCSE Results

\begin{tabular}{|c|c|c|c|c|}
\hline & Model 1 & Model 2 & Model3 & Model 4 \\
\hline & $B$ & $B$ & $B$ & $B$ \\
\hline $\begin{array}{l}\text { Corrected } \\
\text { Model }\end{array}$ & $0.324^{* * *}$ & $0.361^{* * *}$ & $0.383^{* * *}$ & $0.576^{* * *}$ \\
\hline Intercept & $\begin{array}{l}29.521 \\
(2.943)^{\star * *}\end{array}$ & $\begin{array}{l}26.896 \\
(2.910)^{\star * *}\end{array}$ & $\begin{array}{l}22.188 \\
(3.100)^{* * *}\end{array}$ & $\begin{array}{l}7.975 \\
(2.769)^{\star *}\end{array}$ \\
\hline Degree & $\begin{array}{l}7.555 \\
(2.869)^{* *}\end{array}$ & $\begin{array}{l}3.189 \\
(2.921)\end{array}$ & $\begin{array}{l}2.608 \\
(2.877)\end{array}$ & \begin{tabular}{|l|}
-2.929 \\
$(2.429)$
\end{tabular} \\
\hline $\begin{array}{l}\text { Intermediat } \\
\mathrm{e}\end{array}$ & $\begin{array}{l}8.114 \\
(2.831)^{* *}\end{array}$ & $\begin{array}{l}6.636 \\
(2.771)^{*}\end{array}$ & $\begin{array}{l}6.616 \\
(2.726)^{*}\end{array}$ & $\begin{array}{l}2.514 \\
(2.283) \\
\end{array}$ \\
\hline $\begin{array}{l}\text { CSE or no } \\
\text { qualificatio } \\
\text { ns }\end{array}$ & 0 & 0 & 0 & 0 \\
\hline $\begin{array}{l}\text { Service } \\
\text { class - } \\
\text { higher }\end{array}$ & $\begin{array}{l}17.688 \\
(3.196)^{\star \star *}\end{array}$ & $\begin{array}{l}14.047 \\
(3.191)^{\star * *}\end{array}$ & $\begin{array}{l}13.696 \\
(3.141)^{\star * *}\end{array}$ & $\begin{array}{l}10.202 \\
(2.623)^{* * *}\end{array}$ \\
\hline $\begin{array}{l}\text { Service } \\
\text { class - } \\
\text { lower }\end{array}$ & $\begin{array}{l}12.945 \\
(3.016)^{\star \star \star}\end{array}$ & $\begin{array}{l}10.979 \\
(2.960)^{\star * *}\end{array}$ & $\begin{array}{l}11.145 \\
(2.913)^{\star * *}\end{array}$ & $\begin{array}{l}9.261 \\
(2.423)^{\star * *}\end{array}$ \\
\hline $\begin{array}{l}\text { Routine } \\
\text { non- } \\
\text { manual }\end{array}$ & \begin{tabular}{|l|}
9.712 \\
$(2.783)^{\star * *}$
\end{tabular} & $\begin{array}{l}9.000 \\
(2.712)^{\star * *}\end{array}$ & $\begin{array}{l}9.561 \\
(2.672)^{\star * *}\end{array}$ & $\begin{array}{l}8.492 \\
(2.225)^{\star * *}\end{array}$ \\
\hline $\begin{array}{l}\text { Petty } \\
\text { bourgeois }\end{array}$ & \begin{tabular}{|l|}
10.339 \\
$(3.165)^{\star * *}$
\end{tabular} & $\begin{array}{l}8.721 \\
(3.096)^{* *}\end{array}$ & $\begin{array}{l}9.020 \\
(3.047)^{\star *}\end{array}$ & $\begin{array}{l}7.753 \\
(2.533)^{\star *}\end{array}$ \\
\hline $\begin{array}{l}\text { Skilled } \\
\text { manual }\end{array}$ & \begin{tabular}{|l|}
5.114 \\
$(3.163)$ \\
\end{tabular} & $\begin{array}{l}4.828 \\
(3.079)\end{array}$ & $\begin{array}{l}4.560 \\
(3.030) \\
\end{array}$ & $\begin{array}{l}5.426 \\
(2.519)^{*}\end{array}$ \\
\hline $\begin{array}{l}\text { Unskilled } \\
\text { manual }\end{array}$ & 0 & 0 & 0 & 0 \\
\hline Male & $\begin{array}{l}-6.300 \\
(1.973)^{* *}\end{array}$ & $\begin{array}{l}-5.797 \\
(1.922)^{* *}\end{array}$ & $\begin{array}{l}-5.360 \\
(1.895)^{\star *}\end{array}$ & $\begin{array}{l}-6.606 \\
(1.581)^{\star * *}\end{array}$ \\
\hline Female & 0 & 0 & 0 & 0 \\
\hline School 1 & \begin{tabular}{|l|}
4.358 \\
$(2.262)$ \\
\end{tabular} & $\begin{array}{l}3.702 \\
(2.206)\end{array}$ & \begin{tabular}{|l|}
3.340 \\
$(2.172)$ \\
\end{tabular} & $\begin{array}{l}5.061 \\
(1.815)^{\star *}\end{array}$ \\
\hline School 2 & \begin{tabular}{|l}
-1.715 \\
$(2.301)$ \\
\end{tabular} & $\begin{array}{l}-3.280 \\
(2.261)\end{array}$ & $\begin{array}{l}-3.200 \\
(2.225) \\
\end{array}$ & \begin{tabular}{|l|}
-3.624 \\
$(1.868)$ \\
\end{tabular} \\
\hline School 3 & $\begin{array}{l}-8.249 \\
(2.180)^{\star \star \star}\end{array}$ & $\begin{array}{l}-6.952 \\
(2.137)^{\star \star \star}\end{array}$ & $\begin{array}{l}-6.580 \\
(2.104)^{\star *}\end{array}$ & $\begin{array}{l}-5.482 \\
(1.763)^{\star \star}\end{array}$ \\
\hline School 4 & 0 & 0 & 0 & 0 \\
\hline
\end{tabular}




\begin{tabular}{|l|l|l|l|l|}
\hline $\begin{array}{l}\text { Parents' } \\
\text { cultural } \\
\text { activities }\end{array}$ & & 1.187 & 0.687 & 0.296 \\
$(0.234)^{* * *}$ & $(0.262)^{* *}$ & $(0.220)$ \\
\hline Reading & & & $1.604^{* * *}$ & $\begin{array}{l}0.668(0.41 \\
7)\end{array}$ \\
\hline Formal & & & $(0.489)$ & -0.432 \\
& & & $(0.978)$ & $\begin{array}{l}0.318(0.81 \\
0)\end{array}$ \\
\hline Music & & & 0.289 & $0.351(0.90$ \\
& & & $(1.098)$ & $5)$ \\
\hline TV & & & 2.189 & $0.001(0.90$ \\
& & & $(1.077)^{*}$ & $7)$ \\
\hline Cultural & & & & 1.250 \\
Knowledge & & & & $(0.173)^{* * *}$ \\
\hline Vocabulary & & & & 0.657 \\
& & & $0.089)^{* * *}$ \\
\hline $\mathrm{N}$ & 461 & 461 & 461 & 461 \\
\hline
\end{tabular}

